\title{
O saber científico registrado e as práticas de mensuração da informação
}

\section{Leilah Bufrem}

Doutora em ciências da comunicação da USP e pós-doutora pela Universidad Autonoma de Madrid

E-mail: leilah@ufpr.br

Yara Prates

Bacharel em gestão da informação. Gestora da informação na Federação das Indústrias do Estado do Paraná E-mail: Yara.Prates@fiepr.org.br

\section{Resumo}

Este trabalho identifica e discute estudos quantitativos no âmbito das pesquisas em informação. Explora a literatura sobre a investigação científica em ciência da informação e aborda os termos utilizados para definir suas atividades de mensuração. Realiza um levantamento de referências de artigos da área em três fontes bibliográficas especializadas internacionais, no período de 1994 a 2001, com recorte específico relacionado às atividades de mensuração. Utiliza, para tanto, a Base de Dados METRI, construída em Winlsis, especificamente para atender a propósitos deste estudo.

Relaciona a definição da nomenclatura atribuída aos estudos quantitativos e sua aplicabilidade na pesquisa em informação. Identifica o surgimento de novos termos e o emprego deles decorrentes da utilização de suportes diferentes e das características distintas da informação.

Palavras-chave

Estudos quantitativos; Pesquisa em informação; Bibliometria; Infometria.

\section{Recorded scientific knowledge and information measuring practices}

\begin{abstract}
This work identifies and discusses quantitative studies within the scope of researches on information. It explores the literature on scientific investigation on information science and approaches the terms used to define its measuring activities. It searches the references of scientific articles in this field from three different international specialized bibliographic sources from 1994 to 2001, with a view of measuring activities. In order to achieve it, the study used the METRI database, built in Winlsis to serve its purposes. It relates the attributed terminology to quantitative studies and their applicability to research on Information. It identifies the surfacing of new terms and their use, which have originated from the use of different sources and from the distinct characteristics of information.
\end{abstract}

\section{Keywords}

Quantitative studies; Information research; Bibliometrics; Infometrics.

Ci. Inf., Brasília, v. 34, n. 2, p. 9-25, maio/ago. 2005

\section{INTRODUÇÃO}

O inventário das atividades de pesquisa científica de qualquer campo do conhecimento implica, necessariamente, uma seleção criteriosa, diante da grande circulação de mensagens e de informações registradas que, em contínuo crescimento, atestam a capacidade intelectual do homem. Isso porque ele faz de sua própria atividade vital o objeto de sua vontade e de sua consciência (MARX, 1998, p. 157). E, dispondo dessa atividade vital consciente, ao produzir livremente, defronta-se com sua própria produção, a qual analisa e critica. Mas, se as atividades de informar e comunicar têm se transformado em atividades marcadas pela facilidade e rapidez, alimentando o velho sonho da humanidade de exercer o controle sobre o saber, a tarefa crítica nem sempre pode ser exercida a contento pelo acúmulo da massa documentária disponível.

Por sua vez, as transformações dos formatos metodológicos de investigação nos diversos campos do conhecimento também se destacam devido às condições favoráveis ao processo de tratamento, organização, recuperação e transferência das informações e ao desenvolvimento de possibilidades tecnológicas oferecidas ao investigador no seu cotidiano. O campo específico desta pesquisa, a área de ciência da informação, caracteriza-se pela diversidade de fontes e meios de acesso e produção da informação com que trabalha. Nele, o processo de aceleração do desenvolvimento científico, acentuado pelas tecnologias de informação, computação e telecomunicações, favorece as práticas de mensuração da informação e seu fluxo. Esse fenômeno é comentado em recentes trabalhos científicos, registrados em periódicos de âmbito internacional, tais como os de Glanzel e Schoepflin (1999), Noyons, Moed e Luwel (1999), Wormell (1998) e Osareh (1996), entre outros autores destacados em estudos sobre pesquisas quantitativas.

A diversidade e a ampliação das modalidades de pesquisa e dos suportes em que as informações são registradas resultaram na proliferação dos termos utilizados para definir atividades de mensuração na pesquisa informacional. O termo bibliometria, por exemplo, devido ao seu radical, sugere relações semânticas com o suporte livro e, por associação, ao termo biblioteca. Por 
sua vez, termos alternativos, tais como infometria, informetria, cientometria e webometria, entre outros presentes na relação paradigmática que os abrange, representam práticas de mensuração da informação da ciência, ou de suas representações em modalidade convencional ou na Web, definindo com mais especificidade o universo quantificável a que se referem.

Ao oferecer um panorama sobre o desenvolvimento dos conceitos relacionados às atividades de mensuração, presentes na pesquisa científica da literatura na área de ciência da informação, registram-se neste artigo a análise e o mapeamento dessa evolução. As atividades de identificação, análise e mapeamento dos termos representativos da prática de mensuração registrada na literatura visam a esclarecer implicações semânticas, apoiar pesquisadores no desenvolvimento de novas atividades científicas e também proporcionar um elenco de possibilidades de aplicação de instrumentos na mensuração da informação.

Destacam-se, portanto, duas direções epistemológicas neste processo de investigação. Uma delas dirige-se diacronicamente à literatura na área, mais especificamente ao referencial teórico, lócus por excelência para o esclarecimento dos significados dos termos relacionados aos métodos quantitativos. A outra se dirige à literatura mais recente, extraída de uma base de dados denominada PERIO, para identificar as tendências metodológicas relacionadas à pesquisa quantitativa, observadas em trabalhos que utilizam métodos bibliométricos ou infométricos, assim como sua relação com procedimentos inovadores.

Objetivo da investigação em sua primeira vertente é apresentar e discutir conceitualmente a diversidade e os significados dos termos utilizados para caracterizar os métodos quantitativos da pesquisa científica na literatura, em sua evolução. Em relação à segunda vertente, pretende-se identificar, analisar e mapear os termos representativos da prática de mensuração, registrados na literatura produzida na áreas do conhecimento de ciência da informação e indexada em base de dados especialmente construída com essa finalidade.

A expansão dos estudos baseados em análise de conteúdo da literatura observa-se especialmente quando se analisam os principais instrumentos bibliográficos, tais como os abstracts, que arrolam as pesquisas mais recentes sob esse enfoque e evidenciam as características e peculiaridades desses textos. Destacam-se as relações entre esse enfoque e os estudos quantitativos na área de ciência da informação.
O campo de contribuição teórica, composto pelas interpretações de autores sobre os resultados de suas pesquisas, utiliza uma diversidade de termos relacionados aos estudos quantitativos na prática de pesquisa, nem sempre coincidentes em seus significados. Com essa perspectiva, a análise de estudos sobre as técnicas quantitativas permite a identificação das características da literatura, de suas tendências e evolução, e sua importância não reside apenas nos resultados pontuais, mas, como diriam Sanz Casado e Martín Moreno, nas mudanças que se podem observar neles no decorrer do tempo (1997, p. 47). Dessa forma, a reflexão sobre a prática de pesquisa e sobre a terminologia relacionada aos estudos quantitativos presta-se ao conhecimento da área em suas características mais amplas, bem como ao embasamento teórico de novas pesquisas no campo específico do conhecimento a que se destinam.

Foi analisado um corpus selecionado da literatura na área de ciência da informação, à luz de um domínio teórico fundamentado na produção bibliográfica relativa ao tema, indexada em três fontes bibliográficas referenciais na área de ciência da informação: Library E̊ Information Science Abstracts (LISA), Information Science Abstracts (ISA) e Current Awareness Abstracts (CAA). O recorte da pesquisa compreende o período de 1994 a 2001, quando se verificou aumento significativo da aplicação de estudos bibliométricos nas pesquisas, referenciados em uma base de dados denominada PERIO, estruturada em WinIsis e construída pelo grupo de pesquisa Educação, Pesquisa e Perfil Profissional (UFPR) para subsidiar uma metapesquisa na área de ciência da informação (1998). Os itens selecionados compõem um recorte da base, também em ambiente WinIsis, denominado base METRI, para receber somente artigos cujos temas estejam relacionados à pesquisa sobre mensuração, para estudo e análise sobre a natureza, definições e características do tipo de pesquisa em questão.

A seguir, foram identificados e analisados o surgimento na literatura e as definições dadas aos termos bibliometria, cientometria, infometria/informetria e webometria, a partir de sua aplicação na pesquisa científica, desde sua origem. Para essa análise concorreram obras consideradas clássicas de literatura em ciência da informação e artigos teóricos, anteriores ao período compreendido pela base PERIO.

As informações obtidas a partir da estruturação da base de dados METRI foram sistematizadas, sendo discriminados e tabulados os artigos, segundo seu histórico e características, data e local de publicação do estudo, autor e aplicação na pesquisa, para se proceder ao mapeamento dos estudos. 
Por fim, foi realizada uma análise dos dados tabulados, sob uma perspectiva diacrônica, pela qual se procurou estruturar e relatar as práticas quantitativas na pesquisa científica representada pelos itens selecionados.

Também se encontra incorporada ao trabalho uma representação dos artigos selecionados e analisados, em formato tabular.

\section{BIBLIOMETRIA: UM CONCEITO EM EVOLUÇÃO}

A bibliometria, como prática multidisciplinar, começou a ser usada para identificar comportamentos da literatura e sua evolução em contexto e época determinados. Definida pela primeira vez por Otlet, em 1934, como parte da bibliografia "que se ocupa da medida ou da quantidade aplicada ao livro" (1986, p. 20), a bibliometria procura um perfil dos registros do conhecimento, servindo-se de um método quantificável. Volta-se ao estudo de alguns problemas sociológicos, tentando atingir uma realidade concreta. $O$ termo, junção do grego biblion, que significa livro, com o latim metricus e o grego metrikos, que significam mensuração, refere-se a um conceito usualmente definido como um processo de medida relacionada ao livro ou ao documento. $\mathrm{O}$ termo veio a se repetir em outros autores para diversas aplicações, entre elas a que foi dada pelo conhecido estudioso indiano Ranganathan. Em 1948, na Conferência da Aslib, ele apontava para uma área que denominou "biblioteconometria", justificando-a pela quantidade de números com que lidavam as bibliotecas (VANTI, 2002).

Porém, foi somente em 1969, no seminário anual do Documentation Research and Training Centre (DRTC), que ele apresentou um trabalho com alguns exemplos de aplicação da estatística na biblioteconomia. Foi com base neste trabalho de Ranganathan e em pesquisas realizadas no DRTC que Neelameghan (1969) esboçou a aplicabilidade da biblioteconometria, ou bibliometria, como se tornou conhecida (VANTI, 2002, p. 153).

Tratada como ciência bibliográfica por Victor Zoltowski, cujos estudos macrobibliométricos a desenvolvem como ciência concreta, a bibliometria caracteriza-se pela aplicação da análise estatística à produção bibliográfica de uma nação (1986). Mas suas aplicações também têm sido realizadas por pesquisadores para avaliar e descrever estudos em campos específicos do conhecimento científico. Embora essa prática já viesse sendo utilizada desde 1890, sendo chamada de estatística bibliográfica, foi em 1969 que Pritchard propôs a utilização do termo bibliometria. Definiu-a então como a aplicação de métodos matemáticos e estatísticos a livros e outros meios de comunicação, aconselhando sua utilização em todos os estudos que buscassem quantificar o processo de comunicação escrita (PRITCHARD, 1969).

Hoje, comumente associado à medida, voltada a qualquer tipo de documento, o termo está relacionado ao estudo dos processos quantitativos da produção, disseminação e uso da informação e designa também os processos e mecanismos avançados de busca on-line e técnicas de recuperação da informação.

Outra ênfase é atribuída por Sengupta (1992, p. 77) quando define o termo como "organização, classificação e avaliação quantitativa sobre padrões de publicação, provindas de cálculos matemáticos e estatísticos". Sob esse enfoque, a bibliometria adquire o significado técnico relacionado à mensuração e possibilidade de interconexão de aspectos relativos à comunicação. Outros autores citados por ele confirmam esta tese em Bibliometrics, Informetrics, Scientometrics and Librametrics: an overview. É o caso de Potter, que, citado por Sengupta (1992), conceituou essa metodologia como o estudo e a mensuração sobre padrões de publicação e toda forma de comunicação escrita e seus autores. Por sua vez, Nicholas e Ritchie argumentam que o escopo da bibliometria é o provimento de informações sobre a estrutura do conhecimento e sua comunicação (SENGUPTA, 1992).

Ao defini-la como estudo de livros, documentos, revistas, autores e usuários, Macias-Chapula (1998, p. 135) ilustra as aplicações da bibliometria a variáveis como o número de empréstimos (circulação), de citações, ou de extensão de frases e refere-se aos métodos por ela utilizados como ranking, freqüência, ou distribuição. Os estudos bibliométricos não diferem, neste caso, daqueles que mais recentemente têm sido denominados infometria ou informetria, concretizações de esforços voltados a questões como alocação de recursos, tempo ou dinheiro, além das aspirações acadêmicas e científicas relacionadas à metaciência ou metapesquisa.

Assim, a infometria caracteriza-se pelas práticas de mensuração dos aspectos quantitativos de conteúdo em qualquer formato. Utiliza-se de unidades definidas, tais como palavras, documentos, textos, fontes ou bases de dados, como focos de análise, podendo priorizar variáveis como a recuperação, a relevância, a revocação ou outras características da informação que possam ser consideradas relevantes. Com essas finalidades, recorre a métodos estatísticos, tais como modelo vetorial, modelos booleanos de recuperação, modelos probabilísticos, linguagem de processamento, abordagens 
baseadas no conhecimento e tesauros, com o objetivo de melhorar a eficiência na recuperação.

Percebe-se que os aspectos métricos têm favorecido historicamente uma visão pragmática dessa modalidade metodológica, voltada mais à eficácia e flexibilidade de produtos informacionais de centros de informação, constatação claramente exposta no estudo de Morales García (1992, p. 85). Ele identifica algumas áreas de atuação potencial para os estudos bibliométricos, tais como crescimento quantitativo da literatura; obsolescência da informação; eficiência em serviços e produtos de informação em ciência e tecnologia e produção; eficiência de sistemas de informação e estabelecimento de informações em geral; papel de diferentes tipos de documentos, bem como seu significado na comunicação científica; pertinência e relevância da informação; ranking de publicações periódicas por vários parâmetros; papel dos canais informais na comunicação científica; sobreposição de assuntos contidos entre periódicos e publicações seriadas; hábitos de citação de cientistas e crescimento do papel da análise de citação e relações intradisciplinares e interdisciplinares como determinado nas bases de referências bibliográficas.

Entre as áreas correlatas às ciências sociais e físicas, a bibliometria tem sido aplicada igualmente a estudos sociológicos, gerenciamento da informação, biblioteconomia, história, incluindo ciência política, estudos da ciência e dos cientistas, e suas técnicas são constantemente aplicadas para identificar tendências de pesquisa e crescimento do conhecimento em diferentes áreas da ciência; estimar a extensão dos periódicos secundários; identificar usuários de diferentes assuntos; identificar autoria e suas tendências em documentos de vários assuntos; medir a usabilidade dos serviços de disseminação seletiva da informação; conhecer o passado, o presente e as tendências de publicação; desenvolver modelos experimentais correlatos ou similares; identificar periódicos essenciais de diferentes áreas; formular política de aquisição baseada na necessidade com provisão de limites orçamentários; adaptar uma política acurada de armazenagem e descarte; iniciar sistemas efetivos de rede de trabalho multinível; regular a entrada de informação e comunicação; estudar a obsolescência e dispersão da literatura científica; prever a produtividade de editores, autores individuais, organização e países; projetar o processamento de linguagem automática para auto-indexação, autoresumo e autoclassificação e desenvolver normas para a padronização (SENGUPTA, 1992, p. 83).
No Brasil, segundo Urbizagástegui Alvarado (1984), é por volta de 1970 que se inicia a influência dos estudos métricos, sob o estímulo da disciplina Processamento de Dados na Documentação, ministrada no curso de Mestrado em Ciência da Informação, do então Instituto Brasileiro de Bibliografia e Documentação (IBBD), atual Instituto Brasileiro de Informação em Ciência e Tecnologia (Ibict). O fato confere a este instituto a condição de difusor da abordagem bibliométrica no país, a partir desse momento utilizada nos mais diversos campos. Essa influência é perceptível também nos resultados de Bufrem (1996) sobre os enfoques metodológicos das dissertações apresentadas ao curso entre 1972 e 1995. A opção pelos estudos bibliométricos, entre as práticas metodológicas empregadas pelos autores, foi identificada em 58 das 215 dissertações, perfazendo um significativo percentual de $27 \%$ do total, distribuídas em 32 no período de 1972 a 1983 e 26 no período entre 1984 e 1995. Considerando-se que no primeiro período foram defendidas 88 dissertações ( $41 \%$ do total de 215 ) e no segundo, 127 (59\% do total), foi expressivo o número de trabalhos a utilizar o enfoque bibliométrico, especialmente no primeiro período, em que foi utilizado em $32(36,4 \%)$ do total das 88 dissertações defendidas.

Se em alguns casos o foco das avaliações permaneceu orientado para medir os insumos, como verbas e pessoal de pesquisa, crescentemente está se voltando para os indicadores de resultados. Em tudo que se refere à ciência, os métodos bibliométricos e cientométricos tornaramse essenciais, pois se constituem em valiosa ferramenta, tanto para o estudo das questões (distintas) das disciplinas, quanto para a produção científica de um determinado país ou tema. Destacam-se igualmente para estabelecer indicadores de avaliação científica de um autor, um departamento ou universidade, para melhor gestão dos próprios centros de informação, documentação e bibliotecas (SENGUPTA, 1992, p. 79).

As leis bibliométricas mais comumente utilizadas e relacionadas à produtividade científica (Lei de Lotka), à dispersão da produção científica (Lei de Bradford) e à ocorrência de palavras no texto (Lei de Zipf), cujas aplicações originais foram cedendo lugar a modificações e incorporações, estruturaram-se em corpo teórico que justificou o status de ciência ao conjunto de conhecimentos que então se configurava em torno do objeto informação. E, revestido dessa configuração científica, passa a se destacar nos programas de investigação de alguns países, como destaca Wormell (1998), sob perspectivas teóricas ou práticas diferenciadas. Seus resultados, amplamente divulgados, 
referem-se a indicadores das características da literatura, de suas tendências e evolução.

Como novas metodologias para aproximação a um corpo de conhecimento específico, os chamados métodos bibliométricos podem ser complementados pela chamada análise contextual, apresentada por Falkingham e Reeves (1996). O processo consiste na criação de uma base de dados de atributos definidos para cada texto pelo analista, após o que serão procuradas as relações mais interessantes estabelecidas entre os dados. Enquanto uma análise bibliométrica estuda as características externas de documentos de uma área da literatura especializada, a análise contextual deve ser feita por alguém especializado na matéria em questão. Assim, conjugam-se estudos sobre a produção científica em áreas específicas do conhecimento, integrando ciências na aplicação de critérios quantitativos relacionados à produção científica institucional ou individual, por país ou comparada, à média de produtividade, aos indicadores de autoria e co-autoria, aos tipos de documentos e sua distribuição. Esses critérios podem ser analisados por universidade, por autor ou por tema de publicação, assim como pela média de produção apresentada nas atividades de pesquisa, ou ainda pela maior ou menor difusão das publicações. Vislumbra-se, dessa forma, a possibilidade de conhecer, pelo estudo das publicações, o desenvolvimento de área determinada da ciência, em âmbito geográfico específico, com recortes relativos a temáticas, materiais ou períodos específicos. Têm sido realizados também estudos com enfoques comparativos internacionais (SODHA,1993) para analisar tendências da produção científica de autores de diferentes países.

Essas, entre outras possibilidades de estudos quantitativos, oferecem tênue idéia do que se pode realizar com essa tecnologia em termos de investigação sobre as diversas áreas do conhecimento e seus modos de concretização.

\section{CIENTOMETRIA E A PRODUÇÃO DO CONHECIMENTO}

Quando os métodos quantitativos são utilizados para estudar as atividades científicas ou técnicas, do ponto de vista de sua produção ou comunicação, costuma-se denominá-los cientometria, a ciência da ciência. Está associada ao nome de Derek de Solla Price e, mais concretamente, aos seus dois livros, publicados em 1961 e 1964, "Science since Babylon" e "Little science, Big science" respectivamente. Para a construção dessas obras, Solla Price apóia-se em uma série de trabalhos bibliométricos anteriores (CALLON; COURTIAL; PENAN, 1995, p. 9).
As fontes de dados usuais para estas análises são o Science Citation Index (SCI) e o Social Science Citation Index (SCCI), ambos do Institute for Scientific Information (ISI). Para discernir a estrutura intelectual da ciência, técnicas cientométricas têm sido desenvolvidas e usadas e, como conseqüência, aplicam-se a amplo espectro de variáveis ou indicadores, tais como o número de publicações e citações para auxiliar na avaliação do desempenho científico de pesquisadores.

No que diz respeito à sua origem, o termo surgiu na antiga União Soviética e na Europa Oriental, sendo empregado especialmente na Hungria. Entre os primeiros autores a utilizá-lo estão Dobrow e Carennol, em uma publicação do All-Union Institut for Scientific and Thecnical Information (VANTI, 2002). O termo scientometrics é aqui traduzido como cientometria em português, visto que o latino scientia origina também outros vocábulos tais como ciente, científico e cientista. Por esse motivo, embora o termo cienciometria seja mais comumente usado na literatura especializada em português e espanhol, o primeiro termo é uma tradução adequada do neologismo inglês.

Segundo a definição de Tague-Sutickffe (1992), citado por Vanti (2002, p. 154), as pesquisas cientométricas estudam,

por meio de indicadores quantitativos, uma determinada disciplina da ciência. Estes indicadores quantitativos são utilizados dentro de uma área do conhecimento, por exemplo, mediante a análise de publicações, com aplicação no desenvolvimento de políticas científicas. Tenta medir os incrementos de produção e produtividade de uma disciplina, de um grupo de pesquisadores de uma área, a fim de delinear o crescimento de determinado ramo do conhecimento.

De acordo com Spinak (1998, p. 141), pode-se considerar a ciência como um sistema de produção de informação, mais especificamente informação na forma de publicações, considerando-se publicação qualquer informação registrada em formato permanente e disponível para o uso comum e simultâneo. Assim, podese entender a ciência como uma dinâmica que requer insumos e resultados, e a mensuração dessas duas categorias - insumos e resultados - constitui a base dos indicadores por ele chamados cientométricos.

A cientometria compreende, dessa forma, um conjunto de trabalhos consagrados à análise quantitativa da atividade de investigação científica e técnica. Deveria estudar, portanto, não só os recursos e os resultados, mas também as formas de organização na produção de 
conhecimentos e técnicas (CALLON; COURTIAL; PENAN, 1995, p. 9). Como estudo que aplica técnicas bibliométricas na ciência e utiliza-se de métodos matemáticos e estatísticos para investigar as características da pesquisa científica, a cientometria pode ser considerada um instrumento da sociologia da ciência. $O$ termo se aplica tanto às ciências físicas e naturais quanto às ciências sociais, sendo muito mais do que a aplicação de técnicas de mensuração, visto analisar também o desenvolvimento das ciências políticas.

No entanto, chama-se a atenção para a preocupação da comunidade científica em relação ao ritmo acelerado da mudança tecnológica, aos elevados requerimentos para a pesquisa e à percepção generalizada de que o conhecimento se tornou essencial para a geração de riqueza e a promoção do bem-estar social. Essas estão entre as principais razões pelas quais têm sido realizados consideráveis esforços para identificar e produzir indicadores quantitativos da produção científica, embora obviamente estes não supram a carência de um sistema de avaliação mais consistente em relação ao contexto dinâmico e complexo dos conhecimentos científicos.

É certo que os indicadores cientométricos por si só não substituem as análises especializadas, mas com certeza tornam os dados da pesquisa visíveis e analisáveis, colocando ao alcance dos especialistas a informação adequada para que fundamentem suas análises e conclusões. Quanto ao seu mérito, Rousseau (1998, p. 150) afirma que o método cientométrico considera o alcance que as contribuições de um grupo visivelmente têm em relação ao desenvolvimento de novos conhecimentos na frente de pesquisa.

Ao discutir a importância dos modelos para quantificação dos fatos científicos, Trzesniak (1998, p. 159) afirma que "os fenômenos das físicas e das engenharias prestam-se de maneira absolutamente perfeita à quantificação e à modelagem matemática". Questiona, entretanto, as razões pelas quais essas vantagens não se estendem a todas as áreas do conhecimento e mostra que esforços nesse sentido existem em muitas áreas, como a econometria, para a economia; a sociometria, para as ciências sociais e a psicometria, em relação à personalidade e a certas habilidades do ser humano.

Exceção feita à biblioteconomia e à documentação, áreas que muito utilizam métodos bibliométricos, pela familiaridade com o material de análise e pelo conhecimento das técnicas bibliométricas e sua terminologia, as ciências humanas não têm se voltado para essa utilização. Entretanto, um estudo realizado em
1993 por Maria Alcaín e Maria Jesús San Millán para identificar características e tendências bibliométricas em ciências sociais e humanas analisa a produção científica em sua procedência geográfica, evolução cronológica e orientação temática.

Convém ressaltar também que existem trabalhos de especialistas em ciências sociais e humanas, historiadores, por exemplo, que realizam análises quantitativas sobre documentos, similares às das consideradas análises bibliométricas, e, por não conhecerem sua terminologia e as técnicas bibliométricas, dão a essas análises denominação diferente.

\section{Infometria ou informetria}

O termo informetria, de acordo com Brookes, foi introduzido pela primeira vez pelo professor Otto Nacke na Alemanha em 1979, sendo adotado imediatamente por Viniti, na antiga URSS (VANTI, 2002). Em 1987, o termo foi posto em discussão na primeira Conferência de Bibliometria e Aspectos Teóricos de Recuperação da Informação em Diepenbeek, na Bélgica, organizada por Egghe e Rousseau, que consideraram a informetria como um "guarda-chuva" conceitual abrangendo bibliometria e cientometria. Entretanto, Turner (1994) prefere o termo infometria, composto pela abreviação da palavra informação, o qual não considera sinônimo de bibliometria ou cientometria, mas referente à mensuração do impacto do fluxo de informação em organizações sociais de práticas de produção do conhecimento. Ao refletir sobre as definições utilizadas para os termos que representam a quantificação em diversos suportes, Turner não considera o caractere ' $R$ ' um elemento representativo de um novo indicador de mensuração, mas sim uma nova denominação para o "guarda-chuva" usualmente denominado infometria, o qual pessoalmente prefere manter.

Tanto Sengupta (1992, p. 85) quanto Macías-Chapula (1998, p. 135) adotam o termo informetria, o primeiro considerando-a o campo-chave de estudo que fornece informação parcial sobre uma organização complexa, enquanto o segundo lhe atribui maior abrangência em relação à cientometria e à bibliometria, com um escopo tanto mais distinto e representativo, pois "aborda os aspectos quantitativos da informação em qualquer formato, e não apenas registros catalográficos ou bibliografias". Refere-se também a qualquer grupo social e não especificamente aos cientistas. A informetria, nesse caso, é capaz de incorporar, utilizar e ampliar os muitos estudos de avaliação da informação que estão fora dos limites tanto da bibliometria quanto da cienciometria. 
Ao considerar que a informetria se distingue claramente da cientometria e da bibliometria quanto ao universo de objetos e sujeitos que estuda, Vanti reforça essa afirmação, argumentando que ela não se limita apenas à informação registrada, mas também a processos de comunicação informal, ao contrário de Hjotgaard Christensen e Ingwersen (1997), que caracterizam o termo informetria como uma extensão dos estudos bibliométricos (VANTI, 2002 p. 155).

O termo é definido por Irene Wormell (1998, p. 210) como um subcampo emergente da ciência da informação, baseado na combinação de técnicas avançadas de recuperação da informação, com estudos quantitativos dos seus fluxos e técnicas similares para analisar outro tipo de suporte além do livro. Na Dinamarca, o Centre for Informetric Studies, em Copenhagen, visa a aplicar os métodos bibliométricos não somente aos estudos cientométricos e avaliação de pesquisas em ciência e tecnologia, mas também à análise de suas relações sociais, industriais e de outros tipos especiais que requeiram uma extensão das análises bibliométricas tradicionais de modo a contemplar não apenas as comunidades acadêmicas. A autora conclama os profissionais da biblioteconomia e ciência da informação a encarar os desafios dessa nova área de estudos quantitativos, a aprender a explorar as bases de dados também como instrumento para desenvolver trabalhos analíticos, enfatizando como esses profissionais podem desempenhar suas atividades ascendendo às hierarquias de sua profissão, assim como explorando as técnicas infométricas para tomada de decisões e realização de políticas científicas.

\section{Aplicações bibliométricas na Web}

A webometria, definida como o uso de técnicas bibliométricas à World Wide Web (WWW), é um sistema de estudos de relacionamento de diferentes sites na rede. Essa técnica também pode ser usada para mapear (chamada de scientifc mapping na pesquisa bibliométrica tradicional) áreas da Web que se tornaram mais usadas, baseadas no número de vezes que foram lincados por outros websites*.

Como aplicação de métodos informétricos na WWW, pode-se afirmar que a webometria é uma forma de reconhecimento da importância da rede como meio de informação e comunicação para a ciência e a academia, setores aos quais os estudos quantitativos têm servido.

\footnotetext{
* Disponível em: < http://www.gslis.utexas.edu/ palmquis/courses/ biblio.html >. Acesso em 01/03/2003.
}

A autoria do termo, segundo Vanti (2002), pode-se dar a Almind e Ingwersen (1997), que o caracterizam como uma nova área de interesse dentro da infometria. Outro termo atribuído ao conceito é cybermetrics, que, como destaca Smith (1999), ainda citado por Vanti (2002), corresponde ao nome da revista oficialmente apresentada na VI Conferência Internacional de Cientometria e Informetria, em Jerusalém, no ano de 1997.

Dentre as medições que podem ser realizadas no campo da webometria, destacam-se a freqüência de distribuição e as classificações que compreendem categorias tais como homepages pessoais, institucionais ou organizacionais. Podem-se também realizar mensurações em tempos diferentes para comparar a evolução de uma instituição ou país na rede, para calcular o tamanho médio de uma página expressado em bytes, o número médio em links por página e a densidade média por link. Outros tipos de análise referem-se às citações entre páginas, conhecidas como links, hyperlinks ou weblinks, e estes são vistos como indicadores da importância global de um site ou um espaço (VANTI, 2002).

\section{Análise de citação}

Um impulso considerável na área da bibliometria foi dado pela análise de citação, cuja hipótese básica afirma que qualquer ato de citar o autor de artigo anterior é sempre significativo. Segundo pesquisa de Oliveira, Dórea e Domene (1992, p. 239), em 1995 E. Garfield discutia a necessidade de se estabelecer a sistematização da produção científica por meio de indexadores de citações, uma vez que a quantidade destas pode ser considerada indicativo de qualidade do autor e do impacto da produção científica. A proposta de E. Garfield deu origem à criação do Science Citation Index (SCI), publicado pelo Institute for Scientific Information (ISI), na Filadélfia, Estados Unidos, e vem sendo desenvolvida posteriormente em análises fundamentadas nas citações, também utilizadas por sociólogos, historiadores e pesquisadores da ciência (CALLON COURTIAL; PENAN, 1995, p. 11).

Para avaliar e determinar a influência de um único escritor, por exemplo, ou para descrever o relacionamento entre dois ou mais escritores ou pesquisadores, podemse usar seus métodos, e um caminho comum para condução dessa pesquisa é o uso do Social Science Citation Index, do Science Citation Index ou do Arts and Humanities Citation Index*.

* Disponível em: <http://www.gslis.utexas.edu/ palmquis/courses/ biblio.html >. Acesso em 03/03/2003.. 


\section{Indicadores multidimensionais}

Um modo de inovar os procedimentos cientométricos tem sido a utilização não somente dos indicadores unidimensionais, que estudam, segundo Sanz e Martín, uma só característica dos documentos, sem ter em conta qualquer tipo de vínculo comum que possa existir entre eles, mas principalmente dos indicadores multidimensionais, os quais permitem "ter em conta, de forma simultânea, as distintas variáveis ou as múltiplas interrelações observáveis nos documentos" (1997, p. 61). Essas relações podem ser visualizadas graficamente por meio de mapas demonstrativos das conexões existentes entre diversas características da atividade científica.

Com esse enfoque, outros estudos destacam-se, como o de Small (1976), que representou graficamente as relações entre documentos co-citados, e o de Small e Garfield (1986), que permite a visualização das inter-relações entre especialidades científicas, entre outros estudos mais recentes em que são evidenciadas essas múltiplas relações entre investigadores, publicações, disciplinas ou temas de pesquisa. Essas relações podem ser visualizadas graficamente por meio de mapas demonstrativos das conexões existentes entre diversas características da atividade científica (SANZ CASADO; MARTÍN MORENO, 1997, p. 45).

\section{COMPARAÇÃO DAS APLICAÇÕES DOS DISTINTOS MÉTODOS QUANTITATIVOS}

Certo que definições teóricas auxiliam a compreensão das configurações dos métodos; porém, para melhor entendimento, faz-se necessário tentar associar tais métodos à utilização de aplicações concretas dos termos a eles correspondentes. Com fundamentos na anterior análise de literatura, apresentam-se graficamente as relações entre os termos, em sua forma mais ampla e clara, seus objetos de estudo, variáveis, métodos e objetivos, no quadro 1, produzido por Willian McGrath, citado por Macías-Chapula (1998, p. 135).

O quadro 2, a seguir, ilustra o panorama da utilização dos termos representativos dos conceitos relativos às atividades de mensuração, presentes na pesquisa científica da área de ciência da informação. O mapeamento dessa evolução visa a oferecer um retrato conceitual relacionado à prática de mensuração registrada na literatura e suas implicações semânticas.

\section{QUADRO 1}

Tipologia para definição e classificação dos termos

\begin{tabular}{|c|c|c|c|c|}
\hline $\begin{array}{l}\text { Tipologia/ } \\
\text { Subcampo }\end{array}$ & Bibliometria & Cientometria & Informetria/Infometria & Webometria \\
\hline $\begin{array}{l}\text { Objeto de } \\
\text { estudo }\end{array}$ & $\begin{array}{l}\text { Livros, documentos, } \\
\text { revistas, artigos, autores, } \\
\text { usuários. }\end{array}$ & $\begin{array}{l}\text { Disciplinas, assuntos, campos } \\
\text { científicos e tecnológicos, } \\
\text { patentes, dissertações e teses. }\end{array}$ & $\begin{array}{l}\text { Palavras, documentos, banco de } \\
\text { dados, comunicações informais } \\
\text { (inclusive em âmbito não } \\
\text { científico) e homepage na WWW. }\end{array}$ & $\begin{array}{l}\text { Sítios na WWW, (URL, título, tipo, } \\
\text { domínio, tamanho e links) motores } \\
\text { de busca. }\end{array}$ \\
\hline Variáveis & $\begin{array}{l}\text { Número de empréstimos } \\
\text { (circulação) e de } \\
\text { citações, freqüência de } \\
\text { extensão de frases. }\end{array}$ & $\begin{array}{l}\text { Fatores que se diferenciam as } \\
\text { subdisciplinas. Como os } \\
\text { cientistas se comunicam. }\end{array}$ & $\begin{array}{l}\text { Medir a recuperação, relevância e } \\
\text { revocação }\end{array}$ & $\begin{array}{l}\text { Número de páginas por eixo, número de } \\
\text { linhas por eixo, número de links que } \\
\text { remetem ao mesmo sítio, } \\
\text { "sitações", estratégias de busca }\end{array}$ \\
\hline Métodos & $\begin{array}{l}\text { Ranking, freqüência, } \\
\text { distribuição. }\end{array}$ & $\begin{array}{l}\text { Análise de conjunto de } \\
\text { correspondência, co-ocorrência } \\
\text { de termos, expressões, } \\
\text { palavras-chave. }\end{array}$ & $\begin{array}{l}\text { Modelo vetor espaço, modelos } \\
\text { booleanos de recuperação, } \\
\text { modelos probabilísticos, } \\
\text { linguagem de processamento, } \\
\text { abordagens baseada no } \\
\text { conhecimento, tesauros. }\end{array}$ & $\begin{array}{l}\text { Fator de Impacto da Web (FIW), } \\
\text { densidade dos links, "sitações", } \\
\text { estratégias de busca }\end{array}$ \\
\hline Objetivos & $\begin{array}{l}\text { Alocar recursos, pessoas, } \\
\text { tempo, dinheiro. }\end{array}$ & $\begin{array}{l}\text { Identificar domínios de } \\
\text { interesse, compreender como e } \\
\text { quanto os cientistas se } \\
\text { comunicam. }\end{array}$ & $\begin{array}{l}\text { Melhorar a eficiência da } \\
\text { recuperação da informação, } \\
\text { identificar relações entre os } \\
\text { diversos sistemas de informação. }\end{array}$ & $\begin{array}{l}\text { Avaliar o sucesso de determinados } \\
\text { sítios, detectar a presença de } \\
\text { instituições, pesquisadores na rede } \\
\text { e melhorar a eficiência dos motores } \\
\text { de busca na recuperação das informações. }\end{array}$ \\
\hline
\end{tabular}


QUADRO 2

Panorama da utilização dos termos na pesquisa científica

\begin{tabular}{|c|c|c|}
\hline \multirow{2}{*}{ Ano } & \multirow{2}{*}{ Autor } & Referência \\
\hline & & Aplicação na pesquisa \\
\hline \multirow{2}{*}{1980} & \multirow{2}{*}{ PERITZ, B. C. } & $\begin{array}{l}\text { PERITZ, B. C. The methods of Library Science research: some results from a bibliometric survey. Library } \\
\text { Research, v. 2, p. } 251-268,1980 .\end{array}$ \\
\hline & & Estudo do método bibliométrico \\
\hline \multirow[t]{2}{*}{1990} & \multirow[t]{2}{*}{ FORESTI, N. A. B. } & $\begin{array}{l}\text { FORESTI, N. A. B. Contribuição das revistas brasileiras de biblioteconomia e ciência da informação } \\
\text { enquanto fonte de referência para a pesquisa. Ciencia da Informação, Brasília, v. 19, n. 1, p. 53-71, jan. } \\
1990 .\end{array}$ \\
\hline & & Pesquisa bibliométrica sobre pesquisa em periódicos brasileiros na área de ciência da informação \\
\hline \multirow{2}{*}{1992} & \multirow{2}{*}{ SCHWARTZ, C. A } & $\begin{array}{l}\text { SCHWARTZ, C. A. Research significance: behavioral patterns and outcome characteristics. The Library } \\
\text { Quarterly, v. 62, n. 2, p. 123-149, apr. } 1992 .\end{array}$ \\
\hline & & Apresenta rotina de pesquisa e propõe modelo explicativo de metodologias \\
\hline \multirow{2}{*}{1994} & \multirow{2}{*}{ BURRELL, Q.L. } & BURRELL, Q.L. Scientostochastics? Scientometrics, v. 30, n. 2-3, p. 505-509, jul./aug. 1994. \\
\hline & & $\begin{array}{l}\text { Aponta para a necessidade de desenvolver hardwares e softwares para auxiliar na integração entre } \\
\text { teóricos e praticantes }\end{array}$ \\
\hline \multirow{2}{*}{1994} & \multirow{2}{*}{$\begin{array}{l}\text { GIJON, J. L.; } \\
\text { LOPEZ, A. P }\end{array}$} & $\begin{array}{l}\text { GIJON, J. L.; LOPEZ, A. P. [et.al.]. Siete jornadas bibliotecarias en Andalucía. In: Andalucian Libraries } \\
\text { Assembley, held at Huelva. Proceedings, España, v. 89-112, p. 89-112, 12-14 may. } 1994 .\end{array}$ \\
\hline & & Análise quantitativa de citações, linguagem nacionalidade e autoria \\
\hline \multirow{2}{*}{1994} & \multirow{2}{*}{ MAHAPATRA, G } & $\begin{array}{l}\text { MAHAPATRA, G. Correlation between growth of publications and citations: a study based on growth } \\
\text { curves. Annals of Library Science and Documentation, v. 41, n. 1, p. 8-12, mar. } 1994 .\end{array}$ \\
\hline & & Aplica o estudo bibliométrico para avaliar artigos de periódicos na Índia \\
\hline \multirow{2}{*}{1994} & \multirow{2}{*}{ TURNER, W.A. } & $\begin{array}{l}\text { TURNER, W.A. What's in an "R": informetrics or infometrics. Scientometrics, v. 30, n. 2-3, p. 471-480, } \\
\text { jun./aug. 1994. }\end{array}$ \\
\hline & & Aponta a diferença entre infometria e informetria \\
\hline \multirow{2}{*}{1994} & \multirow{2}{*}{$\begin{array}{l}\text { VOVERIENE, O.; } \\
\text { TRUMPIENE, A. }\end{array}$} & $\begin{array}{l}\text { VOVERIENE, O.; TRUMPIENE, A. bibliometrics, scientometrics and informetrics: their relationship } \\
\text { and interactions. IASLIC Bulletin, v. 39, n. 4, p. 175-179, dec. } 1994 .\end{array}$ \\
\hline & & $\begin{array}{l}\text { Discute o desenvolvimento de mensurações da ciência e apresenta definições sobre livrometria, } \\
\text { bibliometria, cientometria e infometria }\end{array}$ \\
\hline \multirow{2}{*}{1994} & \multirow{2}{*}{$\begin{array}{l}\text { ZITT, M.; BASSECOULARD, } \\
\text { E }\end{array}$} & $\begin{array}{l}\text { ZITT, M.; BASSECOULARD, E. Development of a method for detection and trend analysis of research } \\
\text { fronts built by lexical or co-citation analysis. Scientometrics, v. 30, n. 1, p. 333-351, may. } 1994 \text {. }\end{array}$ \\
\hline & & Compara o uso da análise bibliométrica nas áreas de pesquisas correlacionadas \\
\hline
\end{tabular}


QUADRO 2

Panorama da utilização dos termos na pesquisa científica (continuação)

\begin{tabular}{|c|c|c|}
\hline \multirow{2}{*}{ Ano } & \multirow{2}{*}{ Autor } & \multirow[b]{2}{*}{ Aplicação na pesquisa } \\
\hline & & \\
\hline \multirow[t]{2}{*}{1995} & HELANDER, E. & $\begin{array}{l}\text { HELANDER, E. Evaluation activities in the Nordic countries. Scientometrics, v. 34, n. 3, p. 391-400, } \\
\text { nov./dec. } 1995 .\end{array}$ \\
\hline & & Avaliação de estudos bibliométricos nos países nórdicos \\
\hline \multirow[t]{2}{*}{1995} & $\begin{array}{l}\text { MORALES-MOREJON, M.; } \\
\text { CRUZ-PAZ, A }\end{array}$ & $\begin{array}{l}\text { MORALES-MOREJON, M.; CRUZ-PAZ, A. La bibliotecológica, la cienciológica y la ciencia de la } \\
\text { información y sus disciplinas instrumentales: su alcance conceptual. Ciencias de la Información, v. } \\
\text { 26, n. 2, p. 42-46, jun. } 1995 \text {. }\end{array}$ \\
\hline & & Estuda a inter relação entre bibliometria, infometria e cientometria e outras ciências \\
\hline \multirow[t]{2}{*}{1995} & \multirow{2}{*}{$\begin{array}{l}\text { SANCHEZ GARCIA, A. I.; } \\
\text { GARCIA MARCO, J. }\end{array}$} & $\begin{array}{l}\text { SANCHEZ GARCIA, A. I.; GARCIA MARCO, J. La investigación sobre análisis de contenido y los } \\
\text { lenguajes documentales en las publicaciones periódicas españolas de información y documentación } \\
(1983-1994) \text {. Revista Española de Documentación Cientifica, v. 18, n. 2, p. 155-171, } 1995 .\end{array}$ \\
\hline & & Análise da produção bibliográfica sobre análise de conteúdo \\
\hline \multirow{2}{*}{1995} & \multirow{2}{*}{ WARNING, P.; EMERSON, P. } & $\begin{array}{l}\text { WARNING, P.; EMERSON, P. Cocitation analysis: using bibliometrics to bring academics and } \\
\text { information professionals together. LASIE, v. } 25 \text {, n. } 4-5, \text { p. } 84-89 \text {, jan./apr. } 1995 \text {. }\end{array}$ \\
\hline & & Avalia o método de análise de co-citação para revelar tendência na pesquisa \\
\hline \multirow{2}{*}{1996} & \multirow{2}{*}{ BRAUN, T.; GLANZEL, W. } & $\begin{array}{l}\text { BRAUN, T.; GLANZEL, W. International collaboration: will it be keeping alive East European } \\
\text { research? Journal of Intelligent Information Systems, v. 7, n. 1, p. 247-254, sep. } 1996 .\end{array}$ \\
\hline & & Analisa as contribuições internacionais da pesquisa por meio de estudos bibliométricos \\
\hline \multirow{2}{*}{1996} & \multirow{2}{*}{ GLANZEL, W. } & $\begin{array}{l}\text { GLANZEL, W. The need for standards in bibliometric research and technology. Scientometrics, v. } \\
35 \text {, n. } 2 \text {, p. } 167-176 \text {, feb. } 1996 .\end{array}$ \\
\hline & & Padronização na pesquisa bibliométrica para facilitar a comunicação científica \\
\hline \multirow{2}{*}{1996} & \multirow{2}{*}{ HUANWEN, C. } & $\begin{array}{l}\text { HUANWEN, C. A bibliometric study of library and information research in China. Asian Libraries, } \\
\text { v. } 5 \text {, n. } 2 \text {, p. } 30-45,1996 .\end{array}$ \\
\hline & & Análise de conteúdo sobre pesquisa em LIS na China no período 1985-1994 \\
\hline \multirow{2}{*}{1996} & \multirow{2}{*}{ KATZ, J. S. } & $\begin{array}{l}\text { KATZ, J. S. Bibliometric standards: personal experience and lesson learned. Scientometrics, v. } 35, \mathrm{n} \text {. } \\
\text { 2, p. 193-197, feb. } 1996 .\end{array}$ \\
\hline & & Trata da importância de padrões bibliométricos e da comunidade cientométrica \\
\hline \multirow{2}{*}{1996} & \multirow{2}{*}{ MCGRATH, W.E. } & $\begin{array}{l}\text { MCGRATH, W.E. The unit of analysis (objects of study) in bibliometrics and scientometrics. } \\
\text { Scientometrics, v. } 35, \text { n. } 2 \text {, p. } 257-264 \text {, feb. } 1996 \text {. }\end{array}$ \\
\hline & & A importância da análise do objeto de estudo para o desenvolvimento da teoria bibliométrica \\
\hline \multirow{2}{*}{1996} & \multirow{2}{*}{ MOED, H. F. } & $\begin{array}{l}\text { MOED, H. F. Differences in the construction of SCI based bibliometric indicators among various } \\
\text { producers: a first overview. Scientometrics, v. } 35 \text {, n. 2, p. 177-191, Feb. } 1996 .\end{array}$ \\
\hline & & Discute indicadores bibliométricos e necessidade de padronização da área \\
\hline \multirow[t]{2}{*}{1996} & \multirow[t]{2}{*}{ NARIN, F.; HAMILTON, K.S. } & $\begin{array}{l}\text { NARIN, F.; HAMILTON, K.S. Bibliometric performance measures. Scientometrics, v. 36, n. 3, p. } \\
\text { 293-310, jul./ago. } 1996 .\end{array}$ \\
\hline & & Examina o método quantitativo enfocando a bibliometria \\
\hline
\end{tabular}


QUADRO 2

Panorama da utilização dos termos na pesquisa científica (continuação)

\begin{tabular}{|c|c|c|}
\hline \multirow{2}{*}{ Ano } & \multirow{2}{*}{ Autor } & Referência \\
\hline & & Aplicação na pesquisa \\
\hline \multirow{2}{*}{1996} & \multirow{2}{*}{ OSAREH, F } & $\begin{array}{l}\text { OSAREH, F. Bibliometrics, citation analysis and co-citation analysis: a review of literature I. Libri, } \\
\text { v. } 46, \text { n. 3, p. 149-158, set. } 1996 .\end{array}$ \\
\hline & & Estudo do método bibliométrico e análise de citação \\
\hline \multirow{2}{*}{1996} & \multirow{2}{*}{ OSAREH, F. } & $\begin{array}{l}\text { OSAREH, F. Bibliometrics, citation analysis and co-citation analysis: a review of literature II. Libri, } \\
\text { v. } 46, \text { n. } 4 \text {, p. } 217-225 \text {, dec. } 1996 .\end{array}$ \\
\hline & & Estudo do método bibliométrico e análise de citação (continuação do estudo anterior) \\
\hline \multirow[t]{2}{*}{1996} & \multirow{2}{*}{ VAN RAAN, A. F. J } & $\begin{array}{l}\text { VAN RAAN, A. F. J. Advanced bibliometric methods as quantitative core of peer review based } \\
\text { evaluation and foresight exercises. Scientometrics, v. 36, n. 3, p. 397-420, jul./ago. } 1996 .\end{array}$ \\
\hline & & Utiliza o método bibliométrico para avaliar a pesquisa e o seu impacto \\
\hline \multirow[t]{2}{*}{1997} & \multirow{2}{*}{$\begin{array}{l}\text { BUCHANAN, A.L.; HERUBEL, } \\
\text { J-P.V.M. }\end{array}$} & $\begin{array}{l}\text { BUCHANAN, A.L.; HERUBEL, J-P.V.M. Disciplinary culture, bibliometrics, and historical studies: } \\
\text { preliminary observations. Behavioral and Social Sciences Librarian, v. 15, n. 2, p. 37-53, } 1997 .\end{array}$ \\
\hline & & Estuda a bibliometria e suas relações históricas \\
\hline \multirow{2}{*}{1997} & \multirow{2}{*}{ CHAUMIER, J. } & $\begin{array}{l}\text { CHAUMIER, J. La litterature française en information-documentation ou trente-cinq ans (1961- } \\
\text { 1995) de documentographie. Documentaliste, v. } 34 \text {, n. 2, p. 113-115, mar./apr. } 1997 .\end{array}$ \\
\hline & & Estudo bibliométrico de publicações francesas \\
\hline \multirow{2}{*}{1997} & \multirow{2}{*}{$\begin{array}{l}\text { INGWERSEN, P.; } \\
\text { CHRISTENSEN, F. H }\end{array}$} & $\begin{array}{l}\text { INGWERSEN, P.; CHRISTENSEN, F. H. Date set isolation for bibliometric online analyses of } \\
\text { research publications: fundamental methodological issues. JASIS, v. 43, n. 3, p. 205-217, mar. } 1997 .\end{array}$ \\
\hline & & Analisa o vínculo entre a recuperação da informação on-line e a bibliometria \\
\hline \multirow{2}{*}{1997} & \multirow{2}{*}{ KAUR, K... [et.al.]. } & $\begin{array}{l}\text { KAUR, K... [et.al.]. Titles of LIS textbooks and research articles: a bibliometric study. Malaysian? } \\
\text { Journal of Library Information Science, v. 2, n. 1, p. 51-62, jul. } 1997 .\end{array}$ \\
\hline & & Estudo bibliométrico de artigos de pesquisa \\
\hline \multirow{2}{*}{1997} & \multirow{2}{*}{ SIDDIQUI, M. A. } & $\begin{array}{l}\text { SIDDIQUI, M. A. A bibliometric study of autorship characteristics in four international science } \\
\text { journals. International Forum on Information and Documentation, v. 22, n. 3, p. 3-6, jul. } 1997 .\end{array}$ \\
\hline & & Uso de métodos bibliométrico para análise de autoria \\
\hline \multirow[t]{2}{*}{1997} & \multirow[t]{2}{*}{ VAN HOOYDONK, G. } & $\begin{array}{l}\text { VAN HOOYDONK, G. Fractional counting of multiauthored publications: consequences for the } \\
\text { impact of authors. JASIS: Journal of the American Society for Information Science, v. 48, n. 10, p. } \\
\text { 944-945, oct. 1997. }\end{array}$ \\
\hline & & Discute a autoria múltipla na bibliometria \\
\hline \multirow[t]{2}{*}{1998} & \multirow[t]{2}{*}{ KHAN, M.S.I [et al.]. } & $\begin{array}{l}\text { KHAN, M.S.I [et al.]. Library and information science literature in Bangladesh: a bibliometric study. } \\
\text { Malaysian Journal of Library Information Science, v. 3, n. 2, p. 11-34, Dec. } 1998 .\end{array}$ \\
\hline & & Análise estatística e bibliométrica de artigos publicados em Bangladesh 1996-1997 \\
\hline \multirow{2}{*}{1998} & \multirow{2}{*}{ MACIAS-CHAPULA, C. A. } & $\begin{array}{l}\text { MACIAS-CHAPULA, C. A. The role of informetrics and scientometrics in the national and } \\
\text { international perspective. Ciência da Informação, Brasília, v. 27, n. 2, p. 134-140, maio } 1998 .\end{array}$ \\
\hline & & Definição dos termos bibliometria, informetria e cientometria enfocando seu uso e sua prática \\
\hline
\end{tabular}


QUADRO 2

Panorama da utilização dos termos na pesquisa científica (continuação)

\begin{tabular}{|c|c|c|}
\hline \multirow{2}{*}{ Ano } & \multirow{2}{*}{ Autor } & Referência \\
\hline & & Aplicação na pesquisa \\
\hline \multirow[t]{2}{*}{1998} & \multirow{2}{*}{$\begin{array}{l}\text { OLORUNISOLA, R; AKINBORO, } \\
\text { E. O }\end{array}$} & $\begin{array}{l}\text { OLORUNISOLA, R; AKINBORO, E. O. Bibliographic analysis of articles: a study of African } \\
\text { Journal of Library, Archives and Information Science, 1991-1997. Journal of Library, Archives } \\
\text { and Information Science, v. 8, n. 2, p. 151-154, Oct. 1998. }\end{array}$ \\
\hline & & Análise bibliográfica de periódicos africanos (1991-1997) \\
\hline \multirow[t]{2}{*}{1998} & \multirow{2}{*}{$\begin{array}{l}\text { TIJSSEN, J. W; } \\
\text { WIJK, E. }\end{array}$} & $\begin{array}{l}\text { TIJSSEN, J. W; WIJK, E. van. The global science base of information and communication } \\
\text { technologies: bibliometric analysis of ICT research papers. Scientometrics, v. 42, n. 1, p. 41-60, } \\
\text { May. } 1998 \text {. }\end{array}$ \\
\hline & & Comprova a importância do uso de indicadores bibliométricos em conjunto com bases de dados \\
\hline \multirow{2}{*}{1998} & \multirow{2}{*}{$\begin{array}{l}\text { VAN HOOYDONK, G. } \\
\text { MILIS-PROOST, G }\end{array}$} & $\begin{array}{l}\text { VAN HOOYDONK, G.; MILIS-PROOST, G. Measuring impact by a full option method and } \\
\text { the notion of bibliometric spectra. Scientometrics, v. } 41 \text {, n. } 1-2 \text {, p. } 169-183,1998 \text {. }\end{array}$ \\
\hline & & Apresenta um método que utiliza a bibliometria para analisar atividade de produção cientifica \\
\hline \multirow{2}{*}{1998} & \multirow{2}{*}{ VON UNGERN-STERNBERG, S. } & $\begin{array}{l}\text { VON UNGERN-STERNBERG, S. Teaching bibliometrics. Journal of Education for Library } \\
\text { and Information Science, v. 39, n. 1, p. 76-80, jan. } 1998 .\end{array}$ \\
\hline & & Enfatiza a importância do ensino da bibliometria \\
\hline \multirow{2}{*}{1998} & \multirow{2}{*}{ WORMELL, I. } & $\begin{array}{l}\text { WORMELL, I. Informetrics: exploring databases as analytical tools. Database, v. 21, n. 5, p. } \\
\text { 25-30, Oct./Nov. } 1998 .\end{array}$ \\
\hline & & $\begin{array}{l}\text { Definições de informetria comparando com a bibliometria, bases de dados como instrumento de } \\
\text { análise e uso incipiente da webometria na Dinamarca }\end{array}$ \\
\hline \multirow{2}{*}{1999} & \multirow{2}{*}{ CANO, V } & $\begin{array}{l}\text { CANO, V. Bibliometric overview of library and information science research in Spain. Journal } \\
\text { of the American Society for Information Science, v. 50, n. 8, p. 675-680, } 1 \text { Jun. } 1999 .\end{array}$ \\
\hline & & Análise bibliométrica da pesquisa na Espanha \\
\hline \multirow{2}{*}{1999} & \multirow{2}{*}{ GLANZEL, W; SCHOEPFLIN, U. } & $\begin{array}{l}\text { GLANZEL, W; SCHOEPFLIN, U. A bibliometric study of reference literature in the sciences } \\
\text { and social sciences. Information Processing Management, v. 35, n. 1, p. 31-44, Jan. } 1999 .\end{array}$ \\
\hline & & $\begin{array}{l}\text { Calcula a vida média da literatura de periódicos em ciências sociais e conclui que a } \\
\text { padronização bibliométrica utilizada requer uma revisão }\end{array}$ \\
\hline \multirow{2}{*}{1999} & \multirow{2}{*}{$\begin{array}{l}\text { GLANZEL, W; SCHUBERT, A; } \\
\text { CZERWON, H-J. }\end{array}$} & $\begin{array}{l}\text { GLANZEL, W; SCHUBERT, A; CZERWON, H-J. A bibliometric analysis of international } \\
\text { scientific cooperation of the European Union. Scientometrics, v. 45, n. 2, p. 185-202, jun. } 1999 .\end{array}$ \\
\hline & & $\begin{array}{l}\text { Estudo da colaboração científica entre países e uso dos indicadores bibliométricos aplicados à } \\
\text { análise de autoria e co-autoria }\end{array}$ \\
\hline \multirow[t]{2}{*}{1999} & \multirow[t]{2}{*}{ GLANZEL, W.; SCHOEPFLIN } & $\begin{array}{l}\text { GLANZEL, Wolfgang; SCHOEPFLIN, Urs. A bibliometric study of reference literature in the } \\
\text { sciences and social sciences. Information Processing and Management, v. 35, n. 1, p. 31-44, } \\
\text { Jan. } 1999 .\end{array}$ \\
\hline & & Análise de citação \\
\hline \multirow{2}{*}{1999} & \multirow{2}{*}{ HICKS, D. } & $\begin{array}{l}\text { HICKS, D. The difficulty of achieving full coverage of international social science literature } \\
\text { and the bibliometric consequences. Scientometrics, v. 44, n. 2, p. 193-215, feb. } 1999 .\end{array}$ \\
\hline & & Apresenta uma revisão da literatura bibliométrica em ciências sociais \\
\hline
\end{tabular}


QUADRO 2

Panorama da utilização dos termos na pesquisa científica (continuação)

\begin{tabular}{|c|c|c|}
\hline \multirow{2}{*}{ Ano } & \multirow{2}{*}{ Autor } & \multirow[b]{2}{*}{ Aplicação na pesquisa } \\
\hline & & \\
\hline \multirow[t]{2}{*}{1999} & \multirow{2}{*}{$\begin{array}{l}\text { NOYONS, E. C. M.; MOED, H F.; } \\
\text { LUWEL, M. }\end{array}$} & $\begin{array}{l}\text { NOYONS, E. C. M.; MOED, H F.; LUWEL, M. Combining mapping and analysis citation for } \\
\text { evaluative bibliometric purposes: a bibliometric study. Journal of the American Society for } \\
\text { information Science, v. } 50, \text { n. } 2 \text {, p. } 115-131 \text {, feb. } 1999 .\end{array}$ \\
\hline & & Analisa a combinação de elementos dentro de uma análise integrada \\
\hline \multirow{2}{*}{1999} & \multirow{2}{*}{$\begin{array}{l}\text { NOYONS, E. C. M.; MOED, H. F.; } \\
\text { VAN RAAN, A. F. J }\end{array}$} & $\begin{array}{l}\text { NOYONS, E. C. M.; MOED, H. F.; VAN RAAN, A. F. J. Integrating research performance } \\
\text { analysis and science mapping. Scientometrics, v. 46, n. 3, p. 591-604, nov-dec. } 1999 .\end{array}$ \\
\hline & & $\begin{array}{l}\text { Combinam dois pilares da avaliação bibliométrica, análise de performance e mapeamento e } \\
\text { mostra como utilizar uma análise integrada }\end{array}$ \\
\hline \multirow[t]{2}{*}{1999} & \multirow{2}{*}{$\begin{array}{l}\text { NOYONS, E. C. M.; MOED, H.F.; } \\
\text { LUWEL, M. }\end{array}$} & $\begin{array}{l}\text { NOYONS, E. C. M.; MOED, H.F.; LUWEL, M. Combining mapping and citation analysis for } \\
\text { evaluative bibliometric purposes: a bibliometric study. Journal of the American Society for } \\
\text { Information Science, v. 50, n. 2, p. 115-131, Feb. } 1999 .\end{array}$ \\
\hline & & Combina elementos de análises integradas para enriquecer uma análise de pesquisa \\
\hline \multirow{2}{*}{1999} & \multirow{2}{*}{$\begin{array}{l}\text { ROSENDAAL, H.E.; GEURTS, } \\
\text { P.A.T.M }\end{array}$} & $\begin{array}{l}\text { ROSENDAAL, H.E.; GEURTS, P.A.T.M. Scientific communication and its relevance to } \\
\text { research policy. Scientometrics, v. 44, n. 3, p. 507-519, Mar./Apr.. } 1999 .\end{array}$ \\
\hline & & $\begin{array}{l}\text { Relação entre comunicação e pesquisa científica e a função da bibliometria e cientometria nesse } \\
\text { contexto }\end{array}$ \\
\hline \multirow{2}{*}{1999} & \multirow{2}{*}{ SEN, B K. } & $\begin{array}{l}\text { SEN, B K. Symbols and formulas for a few bibliometric concepts. Journal of Documentation, } \\
\text { v. } 55, \text { n. 3, p. } 325-334 \text {, jun. } 1999 .\end{array}$ \\
\hline & & Mudanças no ensino da bibliometria \\
\hline \multirow[t]{2}{*}{1999} & \multirow{2}{*}{$\begin{array}{l}\text { URBIZAGASTEGUI- } \\
\text { ALVARADO, R. }\end{array}$} & $\begin{array}{l}\text { URBIZAGASTEGUI-ALVARADO, R. La ley de Lotka y la literatura de bibliometría. } \\
\text { Investigación Bibliotecológica: Archivonomía, Bibliotecologíia, e Información, v. 13, n. } 27, \mathrm{p} \text {. } \\
\text { 125-141, Jul-Dec. } 1999 .\end{array}$ \\
\hline & & Uso da Lei de Lotka observado na literatura. \\
\hline \multirow{2}{*}{1999} & \multirow{2}{*}{$\begin{array}{l}\text { WELLER, A. C.; HURD, J. M.; } \\
\text { WIBERLEY, S. E. }\end{array}$} & $\begin{array}{l}\text { WELLER, A. C.; HURD, J. M.; WIBERLEY, S. E. Publication patterns of U.S. academic } \\
\text { librarians from } 1993 \text { to 1997. College Research Libraries, v. 60, n. 4, p. 352-362, Jul. } 1999 .\end{array}$ \\
\hline & & Análise bibliométrica de autoria e padrão de comportamento \\
\hline \multirow[t]{2}{*}{2000} & \multirow[t]{2}{*}{ ARENAS, J. L. de } & $\begin{array}{l}\text { ARENAS, J. Licea de. Una visión bibliométrica de la investigación en bibliotecología y } \\
\text { ciencias de la información de América Latina y el Caribe. Revista Española de Documentación } \\
\text { Científica, v. 23, n. 1, p. 45-53, Jan-Mar. } 2000 .\end{array}$ \\
\hline & & Determinar a atividade de publicação dos países da América Latina e Caribe \\
\hline \multirow{2}{*}{2000} & \multirow{2}{*}{$\begin{array}{l}\text { DING, Y.; CHOWDHURY, G. G.; } \\
\text { FOO, S.; QIAN, W }\end{array}$} & $\begin{array}{l}\text { DING, Y.; CHOWDHURY, G. G.; FOO, S.; QIAN, W. Bibliometric Information Retrieval } \\
\text { System (BIRS): a web search interface utilizing bibliometric research results. Journal of the } \\
\text { American Society for Information Science, v. 51, n. 13, p. 1190-1204, } 2000 .\end{array}$ \\
\hline & & $\begin{array}{l}\text { A pesquisa bibliométrica como auxílio à recuperação de informação nas pesquisas em bases na } \\
\text { Web }\end{array}$ \\
\hline \multirow{2}{*}{2000} & \multirow{2}{*}{ WORMELL, I. } & $\begin{array}{l}\text { WORMELL, Irene. Informetrics: a new era of quantitative studies. Education for Information, } \\
\text { v. } 18, \text { n. } 2 / 3, \text { p. } 131-138 \text {, Oct. } 2000 .\end{array}$ \\
\hline & & Surgimento da informetria como uma generalização da bibliometria \\
\hline \multirow{2}{*}{2001} & \multirow{2}{*}{ CLAUSEN, H; WORMELL, I. } & $\begin{array}{l}\text { CLAUSEN, H; WORMELL, I. A bibliometric analysis of IOLIM conferences 1977-1999. } \\
\text { Journal of Information Science, v. 27, n. 3, p. 157-169, } 2001 .\end{array}$ \\
\hline & & Mede o fator de impacto das conferências por meio de análise bibliométrica \\
\hline
\end{tabular}




\section{DISTRIBUIÇÃO CRONOLÓGICA DOS TERMOS UTILIZADOS}

A análise da literatura enseja um mapeamento representativo do surgimento e da evolução de termos utilizados para designar as práticas de mensuração aqui descritas. Para melhor compreensão, apresentam-se a seguir os termos, o autor que primeiro o utilizou e/ou autor que definiu o conceito, a definição do termo com a data de seu aparecimento e a referência da obra que subsidia o mapeamento (quadro 3).

\section{EVOLUCÃO DA APLICACÃO DO MÉTODO BIBLIOMÉTRICO NA PESQUISA EM CIÊNCIA DA INFORMAÇÃO}

O corpus inicial da análise que resultou no presente trabalho consta de 581 artigos publicados entre os anos de
1990 e 2000 e indexados no período de 1994 a 2001 em três bases de dados internacionais: Library Information Science (LISA), Information Science Abstracts (ISA) e Current Awareness Abstracts (CAA). A seleção, de acordo com termos predeterminados de artigos referentes ao uso de indicadores quantitativos na pesquisa científica resultou em 52 artigos, do total acima, como corpus de pesquisa.

Nota-se, na análise por datas de indexação, que na década de 1990 foi inexpressiva a incidência dos estudos quantitativos em relação aos demais temas componentes do corpus de pesquisa inicial. Há duas ocorrências apenas no período de 1990 a 1993, enquanto em 1994 verifica-se a ênfase dada a estudos de cunho principalmente teórico, embora não se abandonem os estudos práticos, dedicados ao tratamento de definições de termos utilizados em pesquisas e análises bibliométricas.

QUADRO 3

Organização cronológica dos termos utilizados na literatura

\begin{tabular}{|c|c|c|c|}
\hline Termo & Autor & Definição & Referência \\
\hline Bibliometria & Otlet & $\begin{array}{l}\text { Utilizou o termo para designar mensuração física do livro } \\
(1934)\end{array}$ & FONSECA (1992) \\
\hline $\begin{array}{l}\text { Biblioteconome- } \\
\text { tria }\end{array}$ & Ranganathan & $\begin{array}{l}\text { Utilizou o termo para definir aplicações de estatística à } \\
\text { biblioteconomia (1948) }\end{array}$ & SENGUPTA (1992) \\
\hline Bibliometria & Pritchard & $\begin{array}{l}\text { "A aplicação de métodos matemáticos e estatísticos a livros } \\
\text { e outros meios de comunicação" (1969) }\end{array}$ & COUTINHO (1991) \\
\hline Bibliometria & Tague-Sutckiffe & $\begin{array}{l}\text { "[...] o estudo dos aspectos quantitativos da produção, } \\
\text { disseminação e uso da informação registrada. A } \\
\text { bibliometria desenvolve padrões e modelos matemáticos } \\
\text { para medir esses processos, usando seus resultados para } \\
\text { elaborar previsões e apoiar tomadas de decisão" (1992) }\end{array}$ & VANTI (2002) \\
\hline Cientometria & Dobrov; Karennnoi & $\begin{array}{l}\text { Os primeiros autores a utilizarem o termo como } \\
\text { quantificação da ciência em uma publicação do All-Union } \\
\text { Institut for Scientific and Tchecnical Information (1969) }\end{array}$ & VANTI (2002) \\
\hline Cientometria & Brookes & $\begin{array}{l}\text { Derivado de Scientometrics, termo aplicado mais } \\
\text { especificamente para a qualificação e análise das atividades } \\
\text { científicas, incluindo a publicação e organização de livros e } \\
\text { periódicos. }\end{array}$ & TURNER (1994) \\
\hline Cientometria & Tague-Sutckiffe & $\begin{array}{l}\text { É o estudo dos aspectos quantitativos da ciência enquanto } \\
\text { uma disciplina ou atividade econômica (...) é um segmento } \\
\text { da sociologia da ciência, sendo aplicada no } \\
\text { desenvolvimento de políticas científicas, incluindo a } \\
\text { publicação e, portanto, sobrepondo-se à bibliometria (1992) }\end{array}$ & VANTI, (2002) \\
\hline Informetria & Nacke & O primeiro autor a utilizar o termo na Alemanha.(1979) & VANTI (2002) \\
\hline Informetria & Sengupta & $\begin{array}{l}\text { Campo-chave de estudo que fornece informação parcial de } \\
\text { uma organização complexa }\end{array}$ & SENGUPTA (1992) \\
\hline Informetria & Wormell & $\begin{array}{l}\text { Subcampo emergente da ciência da informação com } \\
\text { estudos quantitativos dos fluxos da informação }\end{array}$ & WORMELL (1998) \\
\hline Webometria & Almind; Ingwer & Os primeiros a utilizaram o termo (1997) & VANTI (2002) \\
\hline Webometria & Sengupta & $\begin{array}{l}\text { Técnicas similares à informetria podem ser aplicadas na } \\
\text { WWW, como entidades informacionais com hiperlinks }\end{array}$ & SENGUPTA (1992) \\
\hline
\end{tabular}


O ano de 1995 marca preocupações voltadas para a avaliação do método em si e sua relação com as outras ciências, não mais se restringindo a suas aplicações teóricas ou práticas. É, porém, no ano de 1996 que se observa o crescimento significativo dos estudos mensurativos, com preocupações relacionadas à padronização desse tipo de estudos para facilitar a comunicação científica.

Embora o ano seguinte tenha registrado um leve decréscimo quantitativo de artigos indexados relativos aos estudos bibliométricos, a temática mostrou-se constante ao tratar da mensuração da produção científica e suas inter-relações com outras ciências. Apenas em 1998 registra-se o surgimento do termo informetria, na Dinamarca, utilizado por Wormel, e mostra-se incipiente o uso do termo webometria, ampliando-se a ênfase no ensino dos estudos e práticas bibliométricas.

O final da década de 1990, mais precisamente 1999, presencia uma retomada da temática bibliométrica, tendo o ano em questão o maior número de artigos indexados, com diversas ramificações, entre elas a análise da mensuração na pesquisa em informação, padronização, revisão de padrões, ensino bibliométrico, além da constância temática da produção científica. $\mathrm{O}$ ano de 2000, limite de análise, verificou estabilidade numérica de estudos voltados à mensuração da produção científica, sem alterações no quadro analítico inicial.

A análise do ano de 2001 mostrou-se incompleta, visto haver um lapso de tempo entre a publicação do artigo e a indexação do mesmo, o que tornou a produção registrada em tal ano indisponível para análise em sua totalidade.

\section{CONSIDERAÇÕES FINAIS}

Se a análise das mais remotas práticas de utilização das técnicas bibliométricas permite constatar que elas serviam para mensurar fisicamente o livro, observa-se, sob um enfoque diacrônico, que, em seus usos históricos, elas foram expandindo um domínio de aplicação científica hoje dividido em subáreas do conhecimento e de aplicações técnicas. Suas aplicações mais recentes ampliam-se a outros suportes e a diversos campos de conhecimento, atingindo o dinamismo das mais criativas modalidades de expressão dos saberes registrados, virtual ou convencionalmente. Esse processo vem ocorrendo desde as análises de Zoltowisk, constituintes de um campo reconhecido como macrobibliometria, considerado como ciência concreta, e não como simples técnica de mensuração. Em estudo cujo título original é Les cycles de la création intellectuelle et artistique, o autor indica claramente sua postura em relação às marcas do espírito humano nas suas produções. Até o aparecimento da revista Scientometrics, em 1979, muito se produziu, e o termo passou a ser usado com outras conotações por diversos autores. Desde então, surgem definições, objetos e enfoques diferenciados, relacionados não somente ao estudo quantitativo de livros, mas também de outros documentos, tais como revistas, boletins, atas e outros suportes, de entidades ou autores e usuários. Possibilidades de estudos infométricos abrem-se para a exploração de bases de dados on-line, não somente para analisar documentos ou fatos, mas também para traçar as tendências e o desenvolvimento da sociedade, das disciplinas científicas e das áreas de produção e consumo.

São previstas suas aplicações a variáveis como o número de empréstimos (circulação), de citações, ou de extensão de frases, assim como organização, classificação e avaliação quantitativa sobre padrões de publicação, sujeitas a cálculos matemáticos e estatísticos. Ocorrem ainda estudos sobre padrões de publicação e toda forma de comunicação escrita, sempre se considerando que o escopo da infometria é o provimento de informações sobre a estrutura do conhecimento e sua comunicação.

Observa-se, finalmente, com base na análise dos significantes e de suas significações, que não apenas o termo bibliometria referiu-se à mensuração da informação, mas também surgiram outros, tais como infometria, cientometria, webometria, patentometria e seus sinônimos ou similares, como decorrência dos processos de mensuração, tanto de conteúdos informacionais em suportes diferentes, quanto das características distintas da informação, das variáveis a serem avaliadas, dos métodos utilizados para medir e dos objetivos a serem alcançados. Seja apoiando-se no referencial existente, seja realizando investigações para aprimorar metodologias e instrumentos de análise, esses esforços têm contribuído ao estudo das características e comportamento de campos específicos do conhecimento.

A gama de concepções atribuídas aos termos relacionados neste estudo revela, se não uma convergência de significados e aplicações, principalmente a percepção de que os aspectos resultantes da aplicação das estratégias métricas relacionam-se à interdisciplinaridade do pensamento científico e à maturidade da utilização dos métodos métricos para analisar a dimensão coletiva dos saberes construídos pelo homem.

Artigo recebido em 14/04/2005 e aceito para publicação em 05/01/2006. 


\section{Leilah Bufrem / Yara Prates}

\section{REFERENCIAS}

ALCAÍN, M. D.; SAN MILLÁN, M. J. Uso y tendencias de las técnicas bibliomericas bibliométricas em en ciencias sociales y humanas a nivel internacional. Revista Española de Documentación Cientifica, v. 16, n. 1, 1993.

ALMIND, T. C.; INGWERSEN, P. Informetric analysis on the world wide web: methodological aproaches to 'webometrics'. Journal of Documentation, London, v. 53, n. 4, Sept. 1997.

BROOKES, B. C. Biblio, sciento, infor-metrics?: what are we talking about?. In: EGGHE, L.; ROUSSEAU, R. (Ed.). INFORMETRICS 89/ 90, 1989, Amsterdam. Proceedings... Amsterdam: Elsevier, 1990. p. 3143.

BUFREM, L. S. Linhas e tendências metodológicas na produção acadêmica discente do mestrado em Ciência da Informação do IBICT-UFRJ. 1996. 386 f. Tese (Doutorado)- Setor de Ciências Humanas Letras e Artes, Universidade Federal do Paraná, Curitiba, 1996. LUD, 2000

Pesquisa em informação: reflexões sobre o método. Curitiba:

CALLON, M.; COURTIAL, J. P.; PENAN, H. Cienciometría, el estudio cuantitativo de la actividad científica: de la bibliometría a la vigilancia tecnológica. Espanha: Trea, 1995.

COUTINHO, E. Aplicação da lei de Bradford à literatura técnica sobre ferrovia: análise de periódicos e avaliação da base de dados da Rede Ferroviária Federal S. A. Ciência da Informação, Brasília, v. 20, n. 2, jul./dez. 1991.

DOBROV, G. M.; KARENNOI, A. A. The informational basis of scientometrics. In: MIKHAILOV, A. I. (Ed.). On theoretical problems of informatics. Moscou: VINITI/FID, 1969. p. 165-191.

FALKINGHAM, L. T.; REEVES, R. Context analysis: a technique for analyzing research in a field, applied to literature on the management of R\&D at the section level. Scientometrics, v. 42, n. 2, p. 97-120, 1998.

FONSECA, E. N. da. Bibliografia estatística e bibliometria: uma reivindicação de prioridades. Ciência da Informação, Brasília, v. 2, n.1, p. 5-7, 1973.

Bibliometria: teoria e prática. São Paulo: Cultrix, 1986.

GLANZEL, Wolfgang; SCHOEPFLIN, Urs. A bibliometric study of reference literature in the sciences and social sciences. Information Processing and Management, Oxford, v. 35, n. 1, p. 31-44, Jan. 1999.

GRUPO DE PESQUISA. Perio. Curitiba: [s.n.], 1998. Artigos referentes à pesquisa em informação. 1 banco dados. WinIsis 1.4.

HJOREGAARD, F. Christensen; INGWERSEN, P. Data set isolation for bibliometric online analyses of research publications: fundamental methodological issues. Journal of the American Society for Information Science, v. 48, n. 3, p. 205-217, 1997.

KONDO, E. K. Desenvolvendo indicadores estratégicos em ciência e tecnologia: as principais questões. Ciência da Informação, Brasília, v. 27, n. 2, p. 128-133, maio/ago. 1998.

MACÍAS-CHAPULA, C. A. O papel da informetria e da cientometria e sua perspectiva nacional e internacional. Ciência da Informação, Brasília, v. 27, n. 2, p. 134-140, maio/ago. 1998.

MARX, Karl. O trabalho alienado. In: OLIVEIRA, Paulo de Salles (Org.). Metodologia das ciências humanas. São Paulo: Hucitec: Unesp, 1998. p. 151- 163.

MCGRATH, W. What bibliometricians, scientometricians and informetricians study: a typology for definition and classification: topics for discussion. In: INTERNATIONAL CONFERENCE ON BIBLIOMETRICS, SCIENTOMETRICS AND INFORMETRICS,
2., 1989, Ontario. Proceedings... Ontario: The University of Western Ontario, 1989.

MORALES GARCÍA, Ana María. EVASOFT 1.0 sistema automatizado que permite determinar la idoneidad de las publicaciones seriadas sobre la base del Rango Selectivo Multidemensional (RSM). Ciencias de la Información, La Habana, v. 23, n. 4, p. 273-277, 1992.

MORAVCSK, M. J.; MURUGESAN, P. Some results on the function and quality of citations. Journal Information for Social Studies of Science, v. 5 , p. $86-92,1975$.

Bibliometrics. Disponível em: <http:// www.gslis.utexas.edu/ $\sim$ palmquis/courses/biblio.html $>$. Acesso em: 30 jan. 2003.

NOYONS, E. C. M.; MOED, H. F.; LUWEL, M. Combining mapping and analysis citation for evaluative bibliometric purposes: a bibliometric study. Journal of the American Society for Information Science, v. 50, n. 2, p. 115-131, Feb. 1999.

OLIVEIRA, A. C. de; DÓREA, J. G.; DOMENE, S. M. Bibliometria na avaliação da produção científica da área de nutrição registrada no Cibran: período de 1984-1989. Ciência da Informação, Brasília, v. 21, n. 3, set./dez. 1992.

OSAREH, F. Bibliometrics, citation analysis and co-citation analysis: a review of literature I. Libri, v. 46, n. 3, p. 149-158, Sept. 1996.

. Libri, v. 46, n. 4, p. 217-225, Dec. 1996.

OTLET, Paul. O livro e a medida: bibliometria. In: BIBLIOMETRIA: teoria e prática. São Paulo: Cultrix, 1986. p. 19-34.

PRITCHARD, A. Statistical bibliography or bibliometrics?. Journal of Documentation, London, v. 25, n. 4, p. 348-349, Dec. 1969.

ROUSSEAU, R. Indicadores bibliométricos e econométricos para a avaliação de instituições científicas. Ciência da Informação, Brasília, v. 27, n. 2, p. 149-158, maio/ago. 1998.

SANCHO, R.; PASTOR, A.; CRIADO, E. Bibliometric approach to research performance in the field of refractory materials used in iron and steelmaking processes. Scientometrics, v. 24, n. 1, p. 115-136, 1992.

SANTOS, A. R. Metodologia científica: a construção do conhecimento. Rio de Janeiro: DP\&A, 1999.

SANZ CASADO, E.; MARTÍN MORENO, C. Técnicas bibliométricas aplicadas a los estudios de usuarios. Revista General de Información y Documentación, Madrid, v. 7, n. 2, p. 41- 68, 1997.

SENGUPTA, I. N. Bibliometrics, informetrics, scientometrics and librametrics: an overview. Libri, v. 42, n. 2, p. 75-98, Apr.June 1992.

SMALL. H. U. Structural dynamics of scientific literature. Internacional Classification, v. 3, n. 2, p. 67-74, 1976.

GARFIELD, E. The geography of science: disciplinary and national rnappings. Journal of Information Science, n. 11, p. 147-159, 1986.

SMITH, A. A tale two web spaces: comparing sites using web impact factors. Journal of Documentation, London, v. 55, n. 5, p. 577-592, Dec. 1999.

SODHA, R. J. Trends in biomedical publications: US and Japanese authors in US and European journals. Journal of Information Science, v. 19, n. 1, p. 71-73, 1993.

SPINAK, E. Indicadores cientométricos. Ciência da Informação, Brasília, v. 27, n. 2, p. 141-148, maio/ago. 1998.

TAGUE-SUTCKIFFE, J. An introduction to informetrics. Information Processing and Management, Oxford, v. 28, n. 1, p. 1-3, 1992. 
TARAPANOV, K. Técnicas para tomada de decisão nos sistemas de informação. Brasília: Thesaurus, 1995.

TRZESNIAK, P. Indicadores quantitativos: reflexões que antecedem seu estabelecimento. Ciência da Informação, Brasília, v. 27, n. 2, p. 159. 164, maio/ago. 1998

TURNER, W. A. What's in na $\mathrm{r}$ : informetrics or infometrics? Scientometrics, v. 30, n. 2-3, p. 471-480, 1994.

URBIZAGÁSTEGUI-ALVARADO, R. A bibliometria no Brasil. Ciência da Informação, Brasília, v. 13, n. 2, jul./dez. 1984.
VANTI, N. A. P. Da bibliometria à webometria: uma exploração conceitual dos mecanismos utilizados para medir o registro da informação e a difusão do conhecimento. Ciência da Informação, Brasília, v. 31, n. 2, p. 152-162, maio/ago. 2002.

WORMELL, I. Informetrics: exploring databases as analytical tools. Database, v. 21, n. 5, p. 25-30, Oct./Nov. 1998.

ZOLTOWSKI, Victor. Os ciclos da criação intelectual e artística. In: BIBLIOMETRIA: teoria e prática. São Paulo: Cultrix, 1986. p. 71111. 